\title{
Climate change creativity for cirrus clouds and contrails control
}

\begin{abstract}
Cirrus ice clouds formed normally in the upper troposphere and contrails, shed by aircraft, impact climate and global warming due to prevailing cirrus clouds ice water content and crystal size. Contrail cirrus impact on climate change also comprises their influence on water vapor in the higher troposphere layer, which alter the infrared heat emission. The effect of commercial flights to climate change is of serious concern to the environmental conservation and climate change mitigation efforts. Therefore, it is imperative that the physical characteristics of cirrus clouds, contrails and their interactions be understood to devise anthropogenic solutions.
\end{abstract}

Keyword: Aircraft trailing vortices; Cirrus cloud; Climate change; Contrails; Green aircraft technology 